\title{
PRÁTICAS X EDUCAÇÃO AMBIENTAL: OPORTUNIZANDO A CONSCIÊNCIA ECOLÓGICA - RELATO DE EXPERIÊNCIA
}

\author{
Cisnara Pires Amaral ${ }^{1}$
}

\begin{abstract}
RESUMO
Vivemos a frequente preocupação com o processo de educação ambiental, pois entendemos que a sobrevivência da humanidade dependerá de nossa capacidade para entender princípios básicos da ecologia, como interdependência, relações ecológicas e biodiversidade. $\mathrm{O}$ intuito da atividade foi de propiciar atividades práticas com uma turma de $6^{\circ}$ ano de uma escola pública do município de Santiago/RS visando o entendimento entre as relações ecológicas e a importância das abelhas para polinização, produção de alimento; além da percepção dos malefícios do uso de agrotóxicos para a espécie. Para isso, a professora orientadora trabalhou o filme "Bee Movie", enfatizou as relações ecológicas existentes, instigou questionamentos, auxiliou os discentes a confeccionar em biscuit abelhas para doarem a seus familiares, relatando a importância da espécie na manutenção do meio ambiente. Após o trabalho realizado em sala de aula os alunos apresentaram seu trabalho na Feira do Livro do Município onde disponibilizaram informações à população como meio de conscientização. Sendo assim, a atividade promoveu a construção ativa do pensar, o desenvolvimento intelectual, o questionar e reelaborar o conhecimento existente, percebendo a importância das relações ecológicas entre os pares. Os discentes atuaram como disseminadores de conhecimento, entendendo que a educação ambiental poderá ocorrer com troca de informações, que consciência ecológica se produz com atividades simples, desde que bem orientadas. Assim aluno e professor tiveram a possibilidade de perceber que o conhecimento é inesgotável e que não existem respostas prontas, mas oportunidades de crescimento e aprendizado.
\end{abstract}

Palavras-chave: Práticas. Educação ambiental. Consciência ecológica.

\footnotetext{
${ }^{1}$ Universidade Regional Integrada do Alto Uruguai e das Missões e Colégio Estadual Cristóvão Pereira.
} 


\title{
PRACTICES X ENVIRONMENTAL EDUCATION: PROVIDING THE ECOLOGICAL AWARENESS - CASE STUDIES
}

\begin{abstract}
We live the frequent concern with the process of environmental education, because we believe that the survival of humanity depends on our ability to understand basic principles of ecology, as interdependence, ecological relationships and biodiversity. The aim of the activity was to provide practical activities with a sixth-grade class in a public school of the city of Santiago/RS aimed at understanding ecological relationships and the importance of bees for pollination, food production; in addition to the perception of the harm of the use of pesticides for the species. Because of that, the orientated teacher worked the film "Bee Movie", emphasized the existing ecological relations, instigated questions, helped the students to make biscuit bees to raise their families, reporting the importance of species in maintaining the environment. After the work done in the classroom the students presented your work at the Book Fair of the Santiago where provided information about the population as a mean of awareness. Therefore, the activity promoted the construction of active thinking, intellectual development, the questioning and re-shape the existing knowledge, realizing the importance of the ecological relationships among peers. The students acted as disseminators of knowledge, understanding that environmental education can occur with exchange of information, that environmental awareness is produced with simple activities, since targeted. As soon as a student and teacher had the possibility to realize that knowledge is inexhaustible and there are no ready answers, but opportunities for growth and learning.
\end{abstract}

Keywords: Practice. Environmental Education. Ecological awareness

\section{INTRODUÇÃO}

A área ambiental tem prevalência muito grande em nossas escolas, porém geralmente é trabalhada de forma inadequada como um tema estanque, através de livros didáticos ou ações esporádicas. Dessa forma, por que não poderemos trabalhar a consciência ecológica em discentes do ensino fundamental com o objetivo de proporcionar a criticidade, a capacidade de entendimento entre as ações que se desenvolvem no meio e suas consequências?

Bicalho e Oliveira (2009) relatam que o avanço das ciências e das novas tecnologias demandou um novo olhar e postura da sociedade em relação à 
educação, ao desenvolvimento de novas habilidades, às interações socioeconômico-ambientais, às questões culturais e éticas.

O avanço da tecnologia torna o sistema educacional um meio para realizar as mudanças éticas e culturais. Lisboa e Kindel (2012) afirmam que o sistema educacional deve buscar ações e estratégias para que as pessoas entendam as relações atuais de produção e consumo, bem como as futuras implicações, decorrentes da continuidade da utilização dos recursos naturais até a exaustão, que causariam irreversíveis problemas na manutenção da vida em nosso planeta.

Observa-se a responsabilidade da instituição escolar e do docente em transformar a Educação Ambiental, tornando-a acessível aos diferentes indivíduos da comunidade. Assim sendo, Reigota, 2002, p.70-80 assegura:

\begin{abstract}
A tendência da educação ambiental escolar é tornar-se não só uma prática educativa, ou uma disciplina a mais no currículo, mas sim consolidar-se como uma filosofia de educação, presente em todas as disciplinas existentes e possibilitar uma concepção mais ampla dopapel da escola no contexto ecológico local e planetário contemporâneo.
\end{abstract}

Segundo Delizoicov, Angotti e Pernambuco (2009) a escola é espaço de socialização, de inserção em relações sociais externas ao âmbito familiar. Uma das suas finalidades principais é garantir a possibilidade de acesso ao conhecimento sistematizado, e é em torno dessa função que, ao menos em sua atribuição legal, deveriam estar sendo organizadas as atividades escolares. Desse modo, sendo a escola espaço de socialização por que não podemos preparar os discentes para serem disseminadores de informações? Por que não podemos colaborar para que ocorra discernimento entre a importância das relações que se estabelecem no ecossistema? Por que não poderemos desenvolver a criticidade em relação aos desastres que ocorrem no meio?

Esse fazer pedagógico aliado a Educação Ambiental tornará o ambiente "sala de aula" propício para discussões, levantamento de dados, compreensão das transformações ecológicas. Outro desafio para o educador ambiental é a necessidade de atuação efetiva no espaço onde se encontra, desafiando possibilidades, construindo permanentemente novas possibilidades, reflexões que garantam aprendizado e respeito aos recursos naturais. 
O contexto ecológico se confirma na dinâmica das salas de aulas, quando a educação ambiental se faz presente e incorpora a preocupação com a qualidade de vida, investiga as relações interdependentes dos elementos do ambiente, relacionando o conhecimento com a complexidade das questões sociais e ambientais (BICALHO E OLIVEIRA, 2009).

Por conseguinte, as questões sociais e ambientais têm extrema relevância através das disciplinas escolares, pois irão propor a discussão sobre os papéis que cada um possui dentro de seu nicho, sendo uma oportunidade de rever concepções e ações pedagógicas para trabalhar no ensino fundamental, atrelando teoria e prática.

Antunes (2009) salienta que professores que trabalham com crianças do ensino fundamental conhecem seu potencial de participação em atividades que Ihes são significativas.

E a significância depende muito do docente, do tipo de direcionamento que dará a atividade, do objetivo da prática. Em suma, as práticas escolares não podem ser vistas como meras aplicações mecânicas de teorias de aprendizagem. O professor deve, assim, ser reconhecido como detentor de um saber que tem componentes gerais, fortemente dependentes das pesquisas acadêmicas, além de componentes contextuais (BIZZO, 2010).

Portanto, é na escola que se estabelecem as conexões entre professor, aluno e aprendizagem, a aprendizagem requer participação, cooperação, troca de informações, construção de trabalhos educativos que favoreçam o papel da escola como espaço de inclusão de saberes (AZEVEDO e REIS, 2009).

A troca de informações irá propor o entendimento que os conhecimentos de Ciências estão no cotidiano, presentes nos desenhos animados, nas propagandas, nas novelas, nos produtos que consumimos, por meio de imagens, termos, conceitos, ideias e representações. (MARANDINO, SELLES e FERREIRA, 2009).

Assim sendo, as formas de aprender e ensinar são uma parte da cultura que todos devemos aprender e sofrem modificações com a própria evolução da educação e dos conhecimentos que devem ser ensinados (POZO e CRESPO, 2009).

Já dizia Piaget, 1998, p.30 
"O ideal da educação não é ensinar o máximo, maximizar os resultados, mas acima de tudo aprender a aprender, aprender a desenvolver, aprender a continuar a desenvolver após deixar a escola."

É mister que se compreenda que o conjunto de atividades que a escola oferece à sua comunidade coopera para a formação de múltiplas dimensões. Tudo o que vive na escola é currículo. Por este motivo os assuntos devem ser contextualizados, vinculados à realidade, exigindo revisão em nossas práticas e tomada de novos posicionamentos, tanto para aluno quanto para o professor.

Consequentemente, a consciência ecológica é um paradigma que se pode preconceber, mas sua construção implica num processo particular e específico. O docente é fator imprescindível nessa atuação, capaz de auxiliar os discentes a compreender criticamente a sua realidade, selecionando estratégias responsáveis para agir e transformar o meio onde vivem.

Independentemente das diferentes formas de se conceber a Educação Ambiental, precisamos estar conscientes de que a crise ambiental é legítima e fazem-se urgentes: ações que possam restaurar a harmonia entre o ser humano e a natureza; a emergência de uma força poderosa que brote do mais íntimo do nosso ser para a sobrevivência da vida na Terra; a mobilização da política mundial para a conservação do meio ambiente e dos recursos naturais, a sensibilidade e a motivação da humanidade para a ação de controle da degradação ambiental.

\section{MATERIAL E MÉTODOS}

O trabalho foi realizado com turma de 30 alunos do ensino fundamental, com idades entre 10 a 12 anos, localizada em uma escola pública da cidade de Santiago/RS, para isso a professora de Ciências do educandário trabalhou o conteúdo relações ecológicas entre os seres vivos. Após as explicações a turma assistiu o DVD "Bee Movie", onde foram questionados sobre o tipo de interação ecológica entre abelhas e seres humanos, abelhas e flores, abelhas e agrotóxicos. Os discentes responderam um questionário para interpretação do filme e sua relação com o conteúdo estudado. O questionário foi adequado a faixa etária das crianças, utilizou-se "emoji" para que pudessem expressar seu sentimento em relação ao filme e conteúdo trabalhado. Em seguida, os 
alunos foram levados ao laboratório de ciências onde produziram uma abelha em biscuit, que serviria como enfeite para o chimarrão para doarem a seus pais, como disseminadores de informações sobre o inseto e sua importância no meio. A massa de biscuit foi comprada em lojas especializadas para artesanato e tingida nas cores amarelo, preto e vermelho. Foram usados grampos de grampeador para produção de patas e antenas e plástico mais grosso para produção de asas. Foi feita uma base com a massa de biscuit utilizando tampinha de garrafa e colocado um prego no centro, após modelou-se uma flor com a utilização de bolinhas nas cores vermelhas e confeccionou-se uma abelha para ser colocada em cima da flor, simulando a polinização. A atividade contou com 2 horas/aulas para exploração do filme e 4 h/aulas no laboratório de Ciências para confecção dos mimos. Depois da produção os alunos foram convidados a expor seu trabalho na Feira do Livro do Município, onde foram novamente disseminadores, além de explicar como foi produzido o mimo, relataram a importância do inseto e a preocupação com os agrotóxicos, devido à região ser produtora de grãos.

\section{RESULTADO E DISCUSSÃO}

Segue questionário respondido pelos discentes, onde foi relacionado o conteúdo relações ecológicas e o Filme "Bee Movie"

\begin{tabular}{|l|l|l|l|}
\hline $\begin{array}{l}\text { Marque o emoji de acordo com sua compreensão a } \\
\text { respeito do assunto: }\end{array}$ & $\ominus$ & & \\
\hline $\begin{array}{l}\text { Todas as relações que aparecem no filme são } \\
\text { harmônicas? }\end{array}$ & & & \\
\hline $\begin{array}{l}\text { Você conseguiu relacionar a importância das abelhas com } \\
\text { a polinização das flores? }\end{array}$ & & & \\
\hline $\begin{array}{l}\text { Você acredita que o uso de agrotóxicos na nossa região } \\
\text { poderá influenciar na vida desse inseto? }\end{array}$ & & & \\
\hline $\begin{array}{l}\text { Você acredita que a importância das abelhas para a vida } \\
\text { do homem está ligada apenas a produção do mel? }\end{array}$ & & & \\
\hline $\begin{array}{l}\text { O filme deixa claro à importância das abelhas no meio } \\
\text { ambiente? }\end{array}$ & & & \\
\hline
\end{tabular}




\begin{tabular}{|l|l|l|l|}
\hline $\begin{array}{l}\text { Nossas ações são fundamentais para a preservação das } \\
\text { espécies? }\end{array}$ & & & \\
\hline $\begin{array}{l}\text { Você gostou da atividade? Explique por que no pontilhado } \\
\text { abaixo do questionário }\end{array}$ & & & \\
\hline
\end{tabular}

Análise dosresultados dos questionários obtidos com o auxílio dos discentes.

Relacionado à questão $\mathrm{n}^{\circ} 1$ "Todas as relações que aparecem no filme são harmônicas?" 100\% dos discentes marcaram no emoji triste, compreendendo que as relações que ocorrem no meio ambiente e no filme, nem sempre são harmônicas e trazem benefício aos seres envolvidos. Listaram durante conversa informal que algumas pessoas realizavam ações que apareciam no filme tentando matar as abelhas, sem que ao menos apresentassem um risco, alguns relataram que os pais trabalhavam com abelhas na produção de mel, associaram a relação ecológica sociedade com o que foi trabalhado no livro didático, observaram a divisão de trabalho estipulada nessa população.

Em relação à questão 2 "Você conseguiu relacionar a importância das abelhas com a polinização"? Nesse quesito tivemos $98 \%$ dos discentes respondendo com o emoji feliz, entendemos que filmes infantis auxiliam a compreensão dos conteúdos escolares, que além do entendimento, trazem significados, podem ser explorados de diversas formas, auxiliam a compreensão entre a degradação ambiental, colaborando com 0 desenvolvimento da consciência ecológica. Durante a visualização tivemos atenção total das crianças, demonstrando que trabalhar a imaginação e o entretenimento, reforçam conteúdos, estabelecendo a ligação entre a teoria e a prática. Lisboa e Kindel (2012) relatam que estimular a percepção de como se dá o contato humano com os demais seres desse meio e com as riquezas naturais das quais desfruta e depende para a sua sobrevivência é um desafio transdisciplinar. Nesse sentido, a escola tem papel importante na formação de pessoas que consigam perceber, refletir e atuar de maneira consciente em seu meio. Ainda corrobora Dias (2003) Educação Ambiental é um processo permanente no qual os indivíduos e a comunidade tomam consciência do seu meio ambiente e adquirem conhecimentos, valores, habilidades, experiências e 
determinação que os tornem aptos a agir e resolver problemas ambientais, presentes e futuros. Também podemos discutir que nenhum aluno é uma folha de papel em branco em que são depositados conhecimentos sistematizados durante sua escolarização. As explicações e os conceitos que formou e forma, em sua relação social mais ampla do que a de escolaridade, interferem em sua aprendizagem de Ciências (DELIZOICOV, ANGOTTI e PERNAMBUCO, 2009).

Em relação à questão 3: "Você acredita que o uso de agrotóxicos na nossa região poderá influenciar na vida desse inseto? 55\% dos discentes responderam com o emoji triste , 30\% com o emoji de espanto e 15\% com o emoji feliz. Observa-se que ainda não tínhamos por parte de alguns alunos a associação da vida do inseto com o uso de agrotóxicos da região. Após a pergunta a professora repassou aos alunos uma reportagem de um dos jornais do município relatando o desaparecimento das abelhas e a pouca produtividade de mel na região, para que entendessem a associação entre a vida do inseto e a manutenção de seu hábitat. Dessa forma, Antunes (2009) observa que ensinar quer dizer ajudar e apoiar os alunos a confrontar uma informação significativa e relevante no âmbito da relação que estabelecem com uma dada realidade, capacitando-o para reconstruir os significados atribuídos a essa realidade e a essa relação.

O ensino tem como consequência aprendizagem. A partir de uma análise sobre a qualidade ambiental que estamos construindo, é que se torna evidente o quanto vivemos numa sociedade anestesiada, já que as pessoas perderam a sensibilidade consigo mesmas, com os outros e com a natureza. Portanto, a Educação Ambiental propõe uma educação aos sentidos para as coisas do mundo, não necessariamente as obras de Arte, mas também àquelas corriqueiras e cheias de valores para uma vida harmoniosa em que o mundo moderno nos oculta (DUARTE JUNIOR, 2006).

Quanto à questão 4: "Você acredita que a importância das abelhas para a vida do homem está ligada apenas a produção do mel"? 95\% dos discentes responderam com o emoji carinha triste, isso significa que entendem que abelhas são insetos sociais, que possuem inúmeras funções no ecossistema, dentre elas a polinização das flores. $O$ interessante foi perceber que durante 0 tempo todo conseguiam relacionar o filme, a falta de flores em relação ao trabalho das abelhas, as explicações que ocorreram durante a aula. Dessa 
forma, entende-se a importância da atuação do professor como mediador de conhecimento, entendendo que além de conhecimentos científicos, existem conhecimentos cotidianos que auxiliam na prática docente, facilitando a mudança de atitudes. Zabala (2010) ressalta que devemos considerar que se adquiriu um valor quando este for interiorizado e foram elaborados critérios para tomar posição frente àquilo que deve se considerar positivo ou negativo, critérios morais que regem a atuação e a avaliação de si mesmo e dos outros. Nessa situação o professor deixará de ser mero retransmissor de informações e passa a ser um aprendiz/mediador. Por esse motivo, o diálogo é um dos pilares do processo aprendizagem, tanto do educando, quanto do professor. Isso exige repensar a docência, abandonando práticas que reforçam a ideia de poder do professor, detentor do saber, para optar por um modelo de professor dialógico, inserido na perspectiva socrática do enunciado "só sei que nada sei", isto é, aberto ás novas propostas (BICALHO E OLIVEIRA, 2009).

Referente a questão 5 "O filme deixa claro à importância das abelhas no meio ambiente"?

Apesar da maioria das crianças não conhecerem o filme, ocorreu grande aceitação e envolvimento. Quanto ao conhecimento do produto, observamos que o filme foi lançado em 2003 e geralmente às crianças assistem lançamentos, disponíveis nos canais pagos ou nas locadoras. O docente encontra nos filmes infantis uma ferramenta capaz de estimular o aprendizado, realizando a analogia do conteúdo estudado, oportunizando a discussão entre os pares. O docente deve apresentar seus conhecimentos como algo de que vale à pena apropriar-se. Trabalha então, como facilitador para que o aluno possa perceber ou projetar significado pessoal naquilo que seu mestre lhe traz (BÖCK, 2008). Quanto à pergunta relacionada obtivemos 85\% das emoji feliz, compreendendo que filmes infantis são ferramentas de imaginação, de pensar, repensar.

Ferraz e Fusari (2009) observam que é necessário repensar um trabalho escolar consistente, duradouro, no qual o aluno encontre um espaço para o seu desenvolvimento pessoal e social por meio da vivência e posse do conhecimento. A posse do conhecimento envolve a atualização do professor e a busca por novas tecnologias capazes de vencer currículos determinados, encontrando nas redes sociais novas formas de aprendizado. 
Relacionado a questão 6:"Nossas ações são fundamentais para a preservação das espécies?

Obtivemos $96 \%$ dos discentes que marcaram no emoji feliz, isso significa que os discentes têm consciência de suas ações, compreendendo a ligação das ações com consequências futuras. Acredito que devemos investir no ensino fundamental, formar disseminadores de ideias e opiniões, pois em conversa com seus familiares sentem-se motivados a contar a atividade e sua importância. Corrobora Casali (2007) o ensino é a ação específica do educador. Vale lembrar que ensinar é uma palavra de origem latina, que significa na sua origem "imprimir um signo, um sinal, uma marca”. Ensinar na escola é uma tarefa complexa. É uma ação ética, no que concerne aos meios, na medida em que supostamente se aproveita de todos os recursos de informação e comunicação disponíveis. Delizoicov, Angotti e Pernanbuco (2009) declaram que a escola formal é somente um dos espaços em que as explicações e linguagens são construídas. O ser humano, sujeito da sua aprendizagem, nasce em um ambiente mediado por outros seres humanos, pela natureza e por artefanatos materiais e sociais. Aprende nas relações com esse ambiente, construindo tanto linguagens quanto explicações e conceitos, que variam ao longo da sua vida, como resultado dos tipos de relações e de sua constituição orgânica.

Questão 7 " Você gostou da atividade? 100\% dos discentes marcaram os emojis feliz. Em suas explicações relataram que gostam de desenhos, compreenderam melhor a vida das abelhas, entenderam que sem a polinização ficaríamos sem flores, observaram que muitas vezes o ser humano quer matar os animais somente por que não gostam deles. Observa-se que o educador poderá trabalhar a Educação Ambiental sem que esse tema se torne neutro e sem significado, poderá ampliar seu significado para um movimento de pertencimento e co-responsabilidade pela ações que ocorrem no meio.

\section{CONCLUSÃO}

Conclui-se que o professor tem papel fundamental no desenvolvimento da consciência ecológica, que vai além de realizar reaproveitamento de resíduos ou separação de lixo, que deverá atrelar conhecimento e prática, estimular os discentes a desenvolver a criticidade através de ferramentas como filmes 
infantis, trabalhando a ludicidade. Que filmes infantis que abordam temas de degradação ambiental ou associações entre grupos, necessitam ser explorados para que atinjam sua finalidade, promovendo a construção ativa do pensar, o desenvolvimento intelectual, o questionar e reelaborar 0 conhecimento existente, percebendo a importância das relações ecológicas entre os pares.

Também é fundamental considerar que os discentes atuaram como disseminadores de conhecimento, entendendo que a educação ambiental poderá ocorrer com troca de informações, que consciência ecológica se produz com atividades simples, desde que bem orientadas. Assim aluno e professor tiveram a possibilidade de perceber que o conhecimento é inesgotável e que não existem respostas prontas, mas oportunidades de crescimento e aprendizado. A atividade teve como premissa o exercício da cidadania, enfocando o caráter coletivo da responsabilidade de cada ser humano pela sustentabilidade do planeta.

\section{REFERÊNCIAS BIBLIOGRÁFICAS}

ANTUNES, C. Professores e Professauros. 3ํㅗㄹ ed. Petrópolis: Vozes, 2009.

AZEVEDO, J.C.; REIS, J.T. Reestruturação do Ensino Médio.1 $1^{a}$ ed. São Paulo: Fundação Santillana, 2013.

BICALHO, R. S.; OLIVEIRA, P. Construindo o conhecimento: Ecologia. São Paulo: Editora RHJ, 2010.

BIZZO, N. Ciências: fácil ou difícil? 1a ed. São Paulo: Biruta, 2010.

BÖCK, V. R. Motivação para aprender. Motivação para ensinar. Reencantando a escola. Porto Alegre: CAPE, 2008.

CASALI, A. Fundamentos para uma avaliação educativa. In: CAPPELLETTI, Isabel F. Avaliação da aprendizagem: discussão de caminhos. São Paulo: Editora Articulação Universidade/Escola. 2007.

DELIZOICOV, D.; ANGOTTI, J.A.; PERNAMBUCO, M.M. Ensino de Ciências: fundamentos e métodos. $3^{\mathrm{a}}$ ed. São Paulo: Cortez, 2009.

DIAS, G. F. Educação Ambiental: princípios e práticas. 8aa ed. São Paulo: Gaia, 2003. 
DUARTE JUNIOR, J. F. O sentido dos sentidos? A educação (do) sensível. 4ª Ed. Curitiba: Criar Edições, 2006.

FERRAZ, M. H. C. de T, FUSARI, M. F. R. Metodologia do ensino da arte: fundamentos e proposições. $2^{\mathrm{a}}$ ed.- São Paulo: Cortez, 2009.

LISBOA, C.P.; KINDEL, E.A.I. (org.). Educação Ambiental: da teoria à prática. Porto Alegre: Mediação, 2012.

MARANDINO, M.; SELLES, S.E.; FERREIRA, M.S. Ensino de Biologia: história e prática em diferentes espaços educativos. São Paulo: Cortez, 2009.

PIAGET, Jean. A psicologia da criança. Rio de Janeiro: Bertrand Brasil, 1998.

POZO, J.I.; CRESPO, M.A.G. A aprendizagem e o ensino de ciências. $5^{\text {a }}$ ed. São Paulo: Artmed, 2009.

REIGOTA, M. Meio ambiente e representação social. 5. ed. São Paulo: Cortez, 2002.

ZABALA, A. A Prática Educativa: Como ensinar. Porto Alegre: Artmed, 2010. 